\title{
BMJ Open Extended-release nifedipine and the risk of intestinal obstruction: a population-based study
}

\author{
David N Juurlink, ${ }^{1,2,3,4}$ Chelsea Hellings, ${ }^{1}$ Tara Gomes, ${ }^{1,4,5,6}$ Anjie Huang, ${ }^{1}$ \\ J Michael Paterson, ${ }^{1,4}$ David R Urbach, ${ }^{1,4,7}$ Muhammad M Mamdani, ${ }^{1,3,4,5,6,8}$ \\ for the Canadian Drug Safety and Effectiveness Research Network (CDSERN)
}

To cite: Juurlink DN, Hellings C, Gomes T, et al. Extended-release nifedipine and the risk of intestinal obstruction: a populationbased study. BMJ Open 2014:4:e005377.

doi:10.1136/bmjopen-2014005377

- Prepublication history for this paper is available online. To view these files please visit the journal online (http://dx.doi.org/10.1136/ bmjopen-2014-005377).

Received 1 April 2014 Revised 30 June 2014 Accepted 1 July 2014
For numbered affiliations see end of article.

Correspondence to Dr David N Juurlink; dnj@ices.on.ca

\section{ABSTRACT}

Objectives: To examine the risk of bowel obstruction in older adults during treatment with extended-release nifedipine compared with patients treated with amlodipine.

Design: Retrospective cohort study using multiple linked healthcare databases.

Setting: Ontario, Canada from 1 April 1997 to 31 December 2010.

Participants: We identified patients aged 66 years and older who started treatment with Adalat XL, an extended-release nifedipine product employing a tablet delivery system associated with mechanical bowel obstruction. For comparison, we studied patients receiving amlodipine, a long-acting calcium channel blocker that does not utilise the same delivery system and has not been implicated as a cause of bowel obstruction. Propensity score matching was used to ensure similarity of patients receiving the two drugs.

Primary outcome measure: HR for the association between extended-release nifedipine relative to amlodipine and hospitalisation for bowel obstruction during therapy.

Results: Over the 13-year study period, we identified 103657 patients treated with extended-release nifedipine and 204733 patients treated with amlodipine. In these two groups, $591(0.6 \%)$ and 1185 $(0.6 \%)$ of patients were hospitalised for bowel obstruction, respectively. We found no difference in the risk of bowel obstruction among patients treated with extended-release nifedipine compared with amlodipine (HR $1.09,95 \% \mathrm{Cl} 0.96$ to 1.24 ).

Conclusions: Bowel obstruction during treatment with extended-release nidefipine is rare, and the risk is not appreciably greater than that during treatment with amlodipine.

\section{INTRODUCTION}

Nifedipine is a widely used calcium channel blocker most often prescribed for the treatment of hypertension. However, the drug has a short half-life (approximately $2 \mathrm{~h}$ ) and must therefore be given several times each

\section{Strengths and limitations of this study}

No previous controlled studies have explored this phenomenon.

- The population-based nature of the data and the ability to account for all prescriptions for extended-release nifedipine and amlodipine in our cohort.

- Diagnostic coding of bowel obstruction is imperfect. Because few patients with bowel obstruction proceed to surgery, we did not examine surgery as an outcome. Error in classifying patients with bowel obstruction would be similar across comparison groups and would bias the study towards the null finding we observed.

- Our findings apply to patients aged 66 years and older, and may not be generalisable to younger persons.

day. To overcome this limitation, the drug has been marketed in a variety of sustained-release formulations, including Procardia XL and Adalat XL, which are widely used products in the USA and Canada, respectively. These formulations utilise the gastrointestinal therapeutic system (GITS), an innovative mechanism designed to release the drug slowly, allowing once-daily dosing. These tablets are comprised of a dual layer of drug and osmotically-active material enclosed within an insoluble cellulose-based tablet shell. ${ }^{1}{ }^{2}$ After ingestion, water is absorbed into the tablet through a semipermeable membrane, expanding an internal polymer layer. This expansion leads to the slow expression of nifedipine suspension through a hole created by a laser in the tablet's centre.

Bezoar formation secondary to GITS medication shells has been described in the literature following therapeutic use, ${ }^{3}{ }^{4}$ and case reports describe small bowel obstruction as a result of tablet impaction following treatment 
with extended-release nifedpidine. ${ }^{5}{ }^{6}$ It has been speculated that the cellulose shells themselves can, in susceptible patients, lead to mechanical bowel obstruction. Until now, no large-scale studies have examined whether the GITS delivery system is associated with bowel obstruction in routine clinical practice. This is an important topic because nifedipine is a widely used calcium channel blocker, but also because other drugs such as doxazosin and atenolol are delivered using the same system.

We examined the risk of bowel obstruction in older adults during treatment with extended-release nifedipine compared with patients treated with amlodipine, a calcium channel blocker with similar clinical indications but produced in a formulation not associated with bowel obstruction.

\section{MATERIALS AND METHODS}

\section{Setting and data sources}

We conducted a retrospective population-based cohort study between 1 April 1997 and 31 December 2010 among Ontarians aged 66 years or older using linked healthcare databases in Ontario, Canada. Ontario has a population of more than 13 million individuals, all of whom have coverage for physician and hospital services. Individuals above the age of 65 also receive public insurance for prescription drugs.

We identified prescription medications using the Ontario Drug Benefit database, which includes records of prescription medications dispensed to Ontarians aged 65 or older. The Registered Persons Database consists of demographic information, including date of death for all Ontario residents. We identified emergency department visits and hospital admissions using the Canadian Institute for Health Information (CIHI) National Ambulatory Care Reporting System (NACRS) and Discharge Abstract Database, respectively. These databases contain detailed diagnostic and procedural information for all hospital visits in the province. We used the Ontario Health Insurance Plan database to identify physician claims for inpatient and outpatient visits, and the Ontario Cancer Registry to identify cases of bowel cancer in the previous 5 years. Hypertension was identified using the Ontario Hypertension Database. ${ }^{7}$ These databases were linked using anonymised identifiers and are routinely used to study the safety and effectiveness of prescription drugs. ${ }^{8-10}$

\section{Cohort design and propensity-based matching}

We constructed a cohort of patients newly treated with extended-release nifedipine (Adalat XL or Procardia $\mathrm{XL}$ ) as evidenced by no prescription for the drug in the 365 days prior to the index date. The index date was defined as the date of first prescription over the study period. We did not examine the first year of eligibility for prescription drug coverage (age 65) to avoid incomplete medication records. To restrict the analysis to patients newly prescribed nifedipine, we excluded individuals who received any formulation of nifedipine, as well as those prescribed amlodipine in the 365 days prior to the index date. We used amlodipine-treated patients as the comparison group because it is used for similar indications but has a half-life ranging between 30 and $50 \mathrm{~h}$ (in contrast to nifedipine's half-life of $2 \mathrm{~h}$ ), and therefore does not require a special delivery system to permit once-daily dosing.

We identified continuous use based on successive prescription for the same drug, requiring that prescription refills be issued within 1.5 times the days supplied by the previous prescription or 10 days, whichever was greater. Patients were censored if they switched study medications, discontinued treatment, reached the end of the study period (31 December 2010), died, or were observed for a maximum of 5 years, whichever occurred first.

Because patients treated with extended release nifedipine may differ in measured and unmeasured ways from those treated with amlodipine, we used highdimensional propensity score matching to create a comparison group of patients with similar characteristics. For this purpose we used an algorithm based on seven data dimensions, consistent with previous studies,${ }^{11}$ including prescription drug claims (past year; 1-dimension), hospitalisation and emergency department diagnoses and procedures (past 1 year; 4-dimensions), and physician service diagnosis and fee codes (past 1 year; 2-dimensions). The most prevalent 200 codes within each data dimension were selected and prioritised based on their potential to bias the exposure-outcome relation, and the top 500 binary empirical variables were included in the propensity score model. Potential covariates were screened for surrogate exposure variables that were not associated with the outcome, and any such variables were excluded from the propensity score model. Variables forced into the propensity score included age, sex, Charlson score, estimated income quintile, longterm care status, history of myocardial infarction, history of hypertension, number of visits to a physician, gastroenterologist and surgeon in the preceding year, rural location, number of distinct drugs in the preceding year and any history of intestinal malignancy, abdominal surgery or intestinal obstruction. Each patient newly treated with extended release nifedipine was matched to up to two patients newly treated with amlodipine, according to propensity score (within 0.2 SDs), age at cohort entry date (within 1 year), sex and year of cohort entry.

The primary analysis examined the risk of bowel obstruction in older adults following initiation of extended-release nifedipine relative to amlodipine. The outcome of interest was hospital admission for bowel obstruction identified using the International Classification of Disease and Related Problems (ICD) 9th and 10th revisions (ICD-9 560.8 and 560.9 and ICD-10 codes K564, K565 and K566). 
Table 1 Baseline characteristics following high-dimensional propensity score matching

\begin{tabular}{|c|c|c|c|}
\hline Characteristics & $\begin{array}{l}\text { Extended-release } \\
\text { nifedipine } \\
\mathrm{N}=103657\end{array}$ & $\begin{array}{l}\text { Amlodipine } \\
\mathrm{N}=204733\end{array}$ & $\begin{array}{l}\text { Standardised } \\
\text { difference* }^{*}\end{array}$ \\
\hline \multicolumn{4}{|l|}{ Age } \\
\hline Median (IQR) & 74 (69 to 79$)$ & 74 (69 to 79$)$ & 0 \\
\hline Male, N (\%) & 40249 (38.8) & $79112(39)$ & 0 \\
\hline \multicolumn{4}{|l|}{ Income quintile, N (\%) } \\
\hline Quintile 1 (lowest) & 23350 (22.5) & $45519(22.2)$ & 0.01 \\
\hline Quintile 2 & 23494 (22.7) & 46354 (22.6) & 0 \\
\hline Quintile 3 & $20763(20.0)$ & $41050(20.1)$ & 0 \\
\hline Quintile 4 & 18579 (17.9) & 36839 (18.0) & 0 \\
\hline Quintile 5 (highest) & $17088(16.5)$ & 34214 (16.7) & 0.01 \\
\hline Rural location, N (\%) & $14680(14.2)$ & $28784(14.1)$ & 0 \\
\hline \multicolumn{4}{|l|}{ Charlson score, $\mathrm{N}(\%)$} \\
\hline No hospitalisation & $69184(66.7)$ & 135478 (66.2) & 0.01 \\
\hline 0 & $13882(13.4)$ & $27542(13.5)$ & 0 \\
\hline 1 & $9081(8.8)$ & $18248(8.9)$ & 0.01 \\
\hline 2 & $11510(11.1)$ & 23465 (11.5) & 0.01 \\
\hline Long-Term Care Residence, N (\%) & $3166(3.1)$ & $6085(3.0)$ & 0 \\
\hline Number of distinct drugs, Median (IQR) & $7(4$ to 11$)$ & 7 (4 to 11$)$ & 0.01 \\
\hline Number of physician visits in past year, Median (IQR) & 15 (8 to 26$)$ & 15 (8 to 26$)$ & 0.02 \\
\hline Number of cardiologist visits in past year, Median (IQR) & $0(0$ to 1$)$ & $0(0$ to 1$)$ & 0.03 \\
\hline GI specialist in previous year, $\mathrm{N}(\%)$ & $7808(7.5)$ & $15670(7.7)$ & 0 \\
\hline Surgeon in previous year, $\mathrm{N}(\%)$ & $12764(12.3)$ & 25269 (12.3) & 0 \\
\hline Abdominal surgery in 5 years prior to cohort entry, $\mathrm{N}(\%)$ & $5292(5.1)$ & $10808(5.3)$ & 0.01 \\
\hline Bowel obstruction in previous 5 years, $\mathrm{N}(\%)$ & $992(1.0)$ & $1983(1.0)$ & 0 \\
\hline Bowel cancer, N (\%) & $2194(2.1)$ & $4322(2.1)$ & 0 \\
\hline Acute myocardial infarction (AMI), N (\%) & $3283(3.2)$ & $6925(3.4)$ & 0.01 \\
\hline Hypertension, N (\%) & $89729(86.6)$ & $177302(86.6)$ & 0 \\
\hline
\end{tabular}

\section{Statistical analyses}

We used standardised differences to compare baseline characteristics between groups, with differences of less than 0.1 generally indicative of good balance. ${ }^{12}$ We conducted time-to-event analyses using Cox proportional hazards regression to examine the risk of the primary outcome among patients treated with extended release nifedipine relative to amlodipine. The proportional hazards assumption was confirmed by testing the statistical significance of a time-dependent treatment variable, and all models were stratified on the nifedipine-amlodipine pairs to account for the matched nature of the data. Baseline characteristics were well balanced between treatment groups following propensity score matching, and therefore only unadjusted models are reported. All analyses were performed at the Institute for Clinical Evaluative Sciences (http://www. ices.on.ca) using SAS V.9.2 (SAS Institute, Cary, North Carolina, USA).

\section{RESULTS}

During the 13-year study period, we identified 103657 eligible patients newly treated with extended release nifedipine. Of these patients, 39\% ( $\mathrm{N}=40249)$ were men, the median age was 74 years old (IQR 69-79 years) and the majority $(\mathrm{N}=89729 ; 87 \%)$ had a documented claim for hypertension. We matched 102829 (99.2\%) of these patients to at least one patient treated with amlodipine ( $\mathrm{N}=204733)$. Following propensity score matching, there were no appreciable differences in the baseline characteristics of the two groups of patients (table 1).

The median follow-up of patients was 247 days (IQR 60-1061 days) and 323 days (IQR 70-1221 days) for nifedipine and amlodipine users, respectively. Among patients receiving extended-release nifedipine, 591 $(0.6 \%)$ were hospitalised for bowel obstruction following treatment compared with $1185(0.6 \%)$ such hospitalisations among patients receiving amlodipine. We found no significant difference in the risk of bowel obstruction among patients treated with extended-release nifedipine relative to amlodipine (unadjusted HR 1.09, CI 0.96 to 1.24; table 2).

\section{DISCUSSION}

In this population-based study spanning 13 years, we found no increased risk of bowel obstruction among patients treated with extended release nifedipine compared to those treated with amlodipine. This finding is somewhat surprising in light of the extended follow-up in our sample, because several compelling case reports 
Table 2 Cox proportional hazards regression for primary analysis

\begin{tabular}{llllll}
\hline Drug & $\begin{array}{l}\text { Number of } \\
\text { patients }\end{array}$ & $\begin{array}{l}\text { Number of } \\
\text { outcomes (\%) }\end{array}$ & $\begin{array}{l}\text { Follow-up time: } \\
\text { median (IQR) (days) }\end{array}$ & $\begin{array}{l}\text { Total follow-up time } \\
\text { (person-years) }\end{array}$ & $\begin{array}{l}\text { Unadjusted HR } \\
\text { (95\% CI) }\end{array}$ \\
\hline $\begin{array}{l}\text { Amlodipine } \\
\text { Extended-release }\end{array}$ & 204733 & $1185(0.6)$ & $323(70$ to 1221) & 169220 & 1.00 (reference) \\
\begin{tabular}{l} 
Niifedipine \\
\hline
\end{tabular} & 103657 & $591(0.6)$ & $247(60$ to 1061) & 366548 & $1.09(0.96$ to 1.24) \\
\hline
\end{tabular}

describe bezoar formation or obstruction (in some cases, with perforation) apparently due to tablet impaction in patients receiving extended-release nifedipine. No previous controlled studies have explored this phenomenon.

Some limitations of our study merit emphasis. We considered only those instances of bowel obstruction resulting in hospitalisation, although few patients with a clinically important bowel obstruction would avoid hospital admission. Diagnosis of bowel obstruction is not perfectly reliable. Because few patients with bowel obstruction proceed to surgery, we did not examine surgery for bowel obstruction as a defining feature of the outcome. Some persons admitted to hospital with abdominal pain and non-specific imaging findings may receive a diagnosis of bowel obstruction, even if a bowel obstruction is not present. Error in classifying patients with bowel obstruction would be similar across comparison groups and would bias the study towards the null finding we observed. Finally, our findings apply to patients aged 66 years and older, and may not be generalisable to younger persons.

Despite these limitations, our findings suggest that the risk of bowel obstruction during treatment with extended release nifedipine is rare and not appreciably greater than that observed during treatment with amlodipine. The results offer reassurance to clinicians whose patients receive extended release nifedipine, as well as other drugs that are delivered using the GITS delivery system.

\footnotetext{
Author affiliations

${ }^{1}$ The Institute for Clinical Evaluative Sciences, Toronto, Ontario, Canada

${ }^{2}$ Sunnybrook Research Institute, Toronto, Ontario, Canada

${ }^{3}$ Department of Medicine, University of Toronto, Toronto, Ontario, Canada

${ }^{4}$ Institute of Health Policy, Management and Evaluation, University of Toronto, Toronto, Ontario, Canada

${ }^{5}$ Leslie Dan Faculty of Pharmacy, University of Toronto, Toronto, Ontario, Canada

${ }^{6}$ Applied Health Research Center, Li Ka Shing Knowledge Institute of St. Michael's Hospital, Toronto, Ontario, Canada

${ }^{7}$ Department of Surgery, University of Toronto, Toronto, Ontario, Canada

${ }^{8}$ Department of Medicine, St. Michael's Hospital, Toronto, Ontario, Canada
}

Acknowledgements The authors thank Brogan Inc, Ottawa for use of their Drug Product and Therapeutic Class Database.

Contributors DNJ, CH, TG, AH, JMP, DRU and MMM were involved in the study concept and design, analysis and interpretation of data, critical revision of manuscript. AH also involved in the acquisition of data. DNJ and $\mathrm{CH}$ involved in the drafting of the manuscript, critical revision of manuscript. $\mathrm{CH}$ and $\mathrm{AH}$ involved in the administrative, technical or material support.
Funding This study was supported by a grant from the Canadian Institutes of Health Research (Grant Number: ETG 92247) and by the Institute for Clinical Evaluative Sciences, a non-profit research institute funded by the Ontario Ministry of Health and Long-Term Care.

Competing interests MMM has served on advisory boards for Hoffmann-La Roche, GlaxoSmithKline, Pfizer, Novartis, Lilly, Astra Zeneca, Boehringer Ingelheim, and Novo-Nordisk. DNJ is acting as the submission's guarantor.

Ethics approval This study was approved by the Research Ethics Board of Sunnybrook Health Sciences Centre.

Provenance and peer review Not commissioned; externally peer reviewed.

Data sharing statement No additional data are available.

Disclaimer The funders had no role in study design, data collection and analysis, decision to publish, or preparation of the manuscript. The opinions, results, and conclusions are those of the authors, and no endorsement by Ontario's Ministry of Health and Long-Term Care, the Canadian Institutes of Health Research, or by the Institute for Clinical Evaluative Sciences is intended or should be inferred.

Open Access This is an Open Access article distributed in accordance with the Creative Commons Attribution Non Commercial (CC BY-NC 4.0) license, which permits others to distribute, remix, adapt, build upon this work noncommercially, and license their derivative works on different terms, provided the original work is properly cited and the use is non-commercial. See: http:// creativecommons.org/licenses/by-nc/4.0/

\section{REFERENCES}

1. Meredith PA. The unique Adalat story -nifedipine gastrointestinal therapeutic system. Eur Cardiovasc Dis 2007;2007:97-102.

2. Swanson DR, Barclay BL, Wong PS, et al. Nifedipine gastrointestinal therapeutic system. Am J Med 1987;83:3-9.

3. Shaw A, Reddy MS, Yeung J, et al. Barium enema: diagnosis and an unusual discovery. Multiple tablets of Adalat LA 30. Gut 2008;57:827, 849.

4. Niezabitowski LM, Nguyen BN, Gums JG. Extended-release nifedipine bezoar identified one year after discontinuation. Ann Pharmacother 2000;34:862-4.

5. Yeen WC, Willis IH. Retention of extended release nifedipine capsules in a patient with enteric stricture causing recurrent small bowel obstruction. South Med J 2005;98:839-42.

6. Georgopoulos S, Gerdes H. Retention of nifedipine extended release tabs in a patient with a colonic stricture. Am J Gastroenterol 1995;90:2224-6.

7. Tu K, Campbell NR, Chen ZL, et al. Accuracy of administrative databases in identifying patients with hypertension. Open Med 2007;1:e18-26.

8. Gomes T, Redelmeier DA, Juurlink DN, et al. Opioid dose and risk of road trauma in Canada: a population-based study. JAMA Intern Med 2013;173:196-201.

9. Park-Wyllie LY, Juurlink DN, Kopp A, et al. Outpatient gatifloxacin therapy and dysglycemia in older adults. N Engl J Med 2006;354:1352-61.

10. Antoniou T, Gomes T, Mamdani MM, et al. Trimethoprim-sulfamethoxazole induced hyperkalaemia in elderly patients receiving spironolactone: nested case-control study. BMJ 2011;343:d5228.

11. Gomes T, Juurlink D, Mamdani M. Comparative adherence to oxybutynin or tolterodine among older patients. Eur J Clin Pharmacol 2012;68(1):97-9.

12. Mamdani M, Sykora K, Li P, et al. Reader's guide to critical appraisa of cohort studies: 2. Assessing potential for confounding. BMJ 2005;330:960-2. 